\title{
WRITTEN ANALYSIS ON LOCAL FACEBOOK HOUSING ADVERTISEMENT
}

\author{
Robi Kurniawan \\ Sultan Syarif Kasim State Islamic University of Riau, Indonesia \\ robi.kurniawan@uin.suska.ac.id \\ Harum Natasha \\ Sultan Syarif Kasim State Islamic University of Riau, Indonesia \\ harumnatasya@uin.suska.ac.id
}

\begin{abstract}
This study explores a written analysis on Facebook closed group housing advertisements of Central Michigan University (CMU) by formulating generic structure as well as identifying the language features. The generic structure is formulated by applying Swales' moves and steps, while language features (tenses, pronouns, and lexical items) were analyzed by using AntConc software (Anthony, 2014). Generic structures show consistent moves and steps, while analysis on language features reveals that the advertisements are mostly composed in present tense, the pronoun "you" justifies the readers as the audience (30 appearances), and "looking" is the language feature of the set intention. Furthermore, the analysis on generic structures indicates that there are three moves which are consistently employed by the author: set intention with two steps (number and desired occupants), description of the place with three steps (location, cost, and selling points), and invitation to respond with two steps (imperatives and means to communicate). In addition, it is found that each posting is relatively brief with an average of only 96.5 words, 7.7 sentences, and 1.7 sentence fragments. Fragments make up $22 \%$ of total 77 sentences. Although this study has clearly generated valuable findings related to generic structure and language feature, it is still potential to be developed and applied in academic writing setting.
\end{abstract}

Keywords: generic structure, language feature, moves analysis

\section{Introduction}

Researchers have been interested in conducting research on linguistic components in advertisements since some decades ago. Among some studies involved are the study by Bhatia (1993) related to written advertisement analysis, and Paltridge (1996) related to the application of written analysis in a classroom setting. However, there are not abundant studies dedicated to the analysis of web-based written advertisement, especially in the Facebook platform. Therefore, this study potentially generates valuable 
findings in applied linguistics in written communication in this digital era.

There are two areas this study mainly focuses on; generic structures and language features. The generic structures will be described via move analysis, while language features will explore grammar analysis, conciseness, sentence fragments, and run-on sentences. While the latter will explore the tense, particular pronouns, and specific words that are analyzed by using AntConc software (Anthony, 2014), move analysis in this study is operated based on a modification to the "Create a Research Study" (CARS) model developed by Swales (1990) modeling the rhetorical movements of the text as a series of moves and steps.

The identification of "move" and "step" is crucial to genre analysis. Many researchers gave different definitions of "move" and "step." For instance, "moves are discriminative elements of generic structure" (Bhatia, 1993, p.30). Furthermore, Yang and Allison (2003) stated that a move is a semantic unit of text achieving a unified purpose in ESP genre analysis. And the concept of "move" expresses the function and purpose of a segment of text at a more general level, while "step" provides a more detailed rhetorical means of realizing the function of a move.

The CARS model proposes three moves, and each move is followed by some steps. The moves and steps are defined as follows:

- Move 1. This first move is called "Establishing territory." It consists of three steps; they are Step 1 (Claiming centrality), Step 2 (Making topic generalizations), and Step 2 (Reviewing items of previous research).

- Move 2, namely "Establishing a niche," which consists of four optional steps; they are Step 1A (Counter-claiming), Step 1B (Indicating a gap), Step 1C (Question-raising), and Step 1D (Continuing a tradition).

- Move 3, namely "Occupying the niche," which consists of three steps; they are Step 1 (Outlining purposes or Announcing present research), Step2 (Announcing principle findings), and Step 3 (Indicating RA structure) (p. 141).

Furthermore, Swales (2004) defined move analysis as "a discoursal or rhetorical unit that performs a coherent communicative function in a written or spoken discourse" which further composes functional units that are considered as flexible terms of linguistics that served as the theme of the written activity (pp. 228-9). In this study, the structures of the postings in the local Facebook group advertisement are composed of three moves, which become the center of rhetorical movements, within each of which are several consistent steps.

Facebook is an electronic communication platform which is used for various purposes and is mainly for casual interactions among people (Dean, 2014). In this analysis, I do a written analysis of local Facebook housing listings in a group for Central Michigan University (CMU). As a closed group, this site consists of CMU community members who are mostly students and alumni. The listings comprise two purposes: for the persons to offer available places (apartment or house) for rent and for the persons to look for places to rent. In this study, I am focusing on the postings that are aimed at offering places for rent. This kind of posting will be called "advertisements" or "ads" throughout the paper. 
Talking about Facebook in a large sense, it is advisable to see it as a speech community. Bloomfield (1933), as cited in Swales (1990) has said that a speech community is a group of speakers who share similar linguistic principles of behavior. The concept is situated within a discourse community that has intercommunication methods among its members and these methods may vary, but they are not limited to meetings, telecommunications, correspondence, newsletter, conversations, etc. (pp. 23-25). In a narrower sense, a local Facebook housing listing can be considered as one of the smaller units of Facebook speech community or a single discourse community. Based on this notion, local Facebook housing listing fulfills the criteria for a speech community because discourse activities occur within the groups by advertisement postings that have their own generic features which are understandable to the members of the group and contain communication values.

As has been addressed earlier, this type of listing resembles much of the characteristic of an advertisement. Although I can argue that this is more casual and unprofessional, it has some of the characteristics of advertisements mentioned by Bhatia (2004) such as headlines that attract readers' attention, targeting the market, justifying and detailing the product or service (p. 65). The latter is about identifying, describing, and indicating the value of the product or service. These selling points occur in the local Facebook housing listings. Bhatia (1993) termed it "offering incentives" (p. 52). Interpersonal dimensions also play their role in this case. Nyyssonen (2001) notes that all utterances (including written) have interpersonal dimensions which are designed to resonate in the minds of people (p. 122). So when identifying, describing, and indicating the value of the product of the service, the authors usually expose the selling points of the places being offered (products).

A quick analysis will show the conciseness of the local Facebook housing advertisements. Each posting has only seven sentences on average. This is related to the findings of Fortanet, Palmer, and Posteguillo (1999) from a study on linguistic analysis on advertisements on the internet (netvertising). Although the study found 40 statements per advertisement (both sentences and noun-verb), only one or two were found to be full sentences because the rest were just phrases. They state, "among the 20 ads observed, a huge percentage of statements were either one or two sentences long" (pp. 103-104). Therefore, the netvertising was very short, resembling the Facebook group advertisements in this analysis in terms of conciseness.

A study related to netvertising was also carried out by Janoschka (2004), who specifically discussed the involvement of spoken features in a written document. The writer pointed out that even though web-based advertisement was in written form, it has the characteristics of spoken languages. Some of the examples were the use of language simplification and abbreviation, imperative forms, and personal pronoun usage. The writer further mentioned, "this concept of orality, often expressed by directives, create a communicative immediacy, imitating interpersonal communication, which is technically transferred" which is closely related to netvertising.

The significance of this study is that it shows how consistently and effectively the author employs both 
generic structures and language features to meet the author's needs as well as those of the readers even though each posting is relatively short, about sentences on average. In other words, within such a short advertisement, it is interesting to see how the communication between an author and reader could be effective. Swales (1990) indicated that the written discourse and communicative events should have communication values by mentioning move as "constraints on allowable contributions in terms of their intent, positioning, form and functional value" (p. 46). Bhatia (1993) depicted this concept as the writers being flexible when using linguistic resources as they wish, but having to adhere to specifically standardized practices within the borderline of a specific genre for not making the communication look odd (p. 50-51).

This study can also give pedagogical value the results translate to a basis for teaching. Paltridge (1996) has said that students of English for Academic Purpose (EAP) can be given a number of genre and text type categories and asked to choose a category for a particular text. They can also be given a list of generic and text structure components and be instructed to locate them within the text. Some of the activities that the students can do are analyzing essays, lectures, and debates related to the sameness and the distinction of the texts, in relation to generic structures and the text types. Students can also be productive by involvement in creating texts, based on the language and discourse patterns that they found in the text. Some additional alternatives include having the students analyze assignment and examination questions to determine a suitable text type for the particular question (pp. 241-242). These teaching ideas can be applied in ESP classrooms with various genres and creatively modified strategies.

\section{Method}

This study is aimed at formulating a generic structure and analyzing the language features of Facebook group housing advertisements. There are two methods of formulation and analysis that will be employed in this study to reveal the generic structure and language features. They are move analysis related to the Create a Research Space (CARS) model adapted from Swales (1990) which is the use of moves and steps to show rhetorical movements of the text ( $p$. 141) and computer-assisted analysis using Anthony's AntConc (2014) software to investigate the language features along with lexical characteristics of the samples. Swales' model uses three moves, each of which are accompanied by three steps; this study will adopt the same approach. The results will be explained in Result and Discussion section.

The analysis involves ten samples from closed groups of Facebook housing listing. The samples are from the same month: October 2015. The time is marked as the beginning of school year at Central Michigan University (CMU). The reason for choosing those samples from that specific time span is to see the way the postings were created when the school semester is started. People (mostly students) who posted during that time of semester had already rented an apartment which consists of more than one bedroom and hoped to sublease the remaining room(s). 


\section{Results and Discussion}

\subsection{Generic Structure}

\section{A. Moves}

The heading and body sections have become the most commonly analyzed for identifying generic features because most discourse activities take place in these sections and generate generic structures of the postings. There are two main parts of move analysis in this section: move and step. "Moves" express the function and purpose of a segment of text at a more general level; moves in this framework denote the general level of "intention," "apartment description," and "invitation to respond." Those moves are followed by "steps," more detailed rhetorical means for accomplishing the functions of the moves. The complete framework is shown in Figure 1.
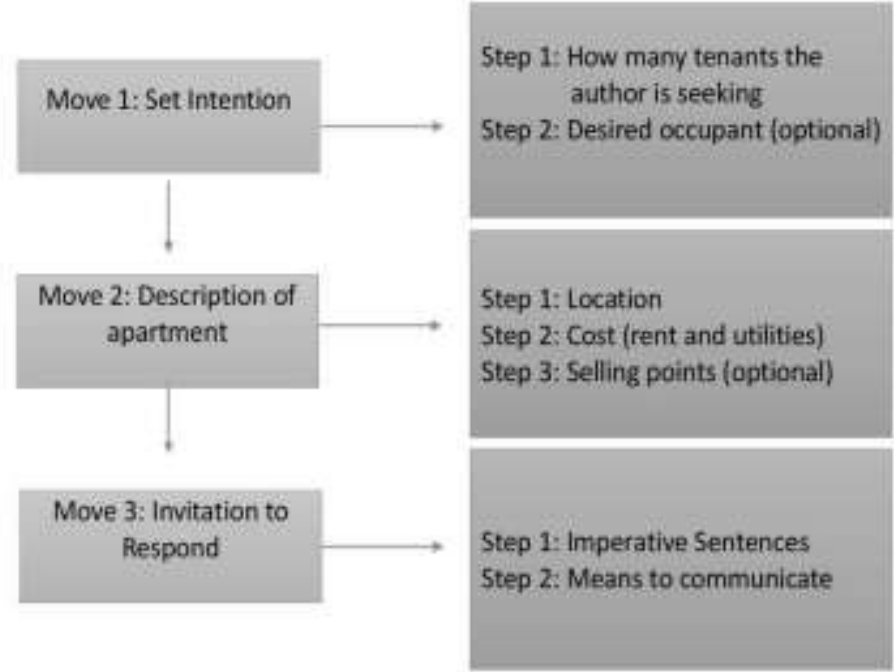

Figure 1. Move analysis

Set intention in Move 1 is the title as well as the purpose of the author. As has been pointed out in the heading section, this move has its characteristic in mentioning the need by having two steps: how many tenants the author is seeking and the gender of the desired occupant (whether male or female). In addition, this also tells the reader the cut-off date for this offer, such as "May 2016" in sample 2 and "Spring Semester" in sample 7 as an optional third step.

In Move 2, the author is describing the apartment. This tells what kind of apartments and how many bedrooms and bathrooms are available. One of the first things described is the location of the apartment (Step 1). Afterward, the author is mentioning a more detailed cost which usually includes the utilities (Step 2). This allows the readers to know the overall payment of the apartment. Usually, there are selling points to back up statements related to price, which is the third step (Step 3). For example, "The rent here is $\$ 310$ a month (going from January 15th- February 15th, and so on).... Also I will pay the sub-lease fee 
and half of the first month's rent (\$155)" in Sample 8.

It is interesting to see how selling points function not only as one of a single step in Move 2, but also as important features in this genre that have pointed out by Bhatia (1993) who called it as "offering incentives" (p. 52). Of all selling points presented in the sentence, there are at least five major themes where the selling points could be incorporated. They lie in location, house condition, service, price, and furniture. The theme of location is expressed as "located walking distance" (sample 1). The house condition theme is shown as "very clean and looks nice" (sample 3). The service theme is expressed as "Free laundry on site" (sample 6). The price theme is conveyed as "This includes everything" (sample 2). And the last theme, which is related to furniture, is communicated as "Apt is partially furnished" (sample 4).

In Move 3, which is an invitation to respond, the author usually uses imperative sentence(s) and mentions how to communicate if someone is interested in the ads. For example in sample 1 the author is asking to call if someone wants to get further information as "Contact Tyler at phone number if you are interested..." (sample 1) or asking to write a message as "Message me if you are interested" (sample 3) to get more information.

\subsection{Language Feature}

Analysis of language features on Facebook housing listing focuses on three areas: (1) tenses used throughout the samples and their lexical analysis (pronoun "you", and the word "look"), (2) conciseness, and (3) grammar analysis.

\section{A. Tenses and lexical analysis.}

Present tense was used throughout the postings. However, there were some present variations which are employed by the authors, such as progressive and modal forms. For example, "The rent is $\$ 450 /$ month but I am willing to negotiate and pay a portion of the rent every month" (sample 7), and "we can talk more or you can just come out and see the place if you want" (sample 1). It is seen from the samples that the use of present forms is consistent in the discourse.

A deeper analysis on the theme of this Facebook housing listing site will give readers an idea of what the postings are about and, more importantly, to see the audience of the postings. To determine who the subjects in the sentences are, Martin and Rose (2007) offered a phase taking and dividing the discourse into clauses ( $p$. 190). This means all of the phrases are listed in order and the subjects of the phrases are determined.

The most frequent pronoun type that appeared in the sample is the pronoun "you" which showed up in all samples with total 27 hits. For example, "I look forward to doing business with you" (sample 1). Please keep in mind that by using computational analysis programs like AntConc (2014), an analyst can only track the available words. However, Martin and Rose (2013) suggest counting "implied" elements, so there are several other "hidden" pronoun "you" which I have also addressed in sentence fragment analysis earlier. For instance, "[You] only have to pay electricity $(\sim 20 / \mathrm{mo})$ and internet if you want it" (Sample 3). So, the total number of 30 words made up $3.1 \%$ of the total 965 words. This number is a significant finding; it can be inferred that the audience of this posting is the readers, and we can see that the 
posting is addressing them directly. Although there is no word limit in the description, this local Facebook housing listing is intended for a specific group of people, in this case, Central Michigan University students (perhaps alumni still exist in the group). The discourse role of the author is evident: someone who offers a place for lease. With this notion, therefore, the readers are the audience of this genre. From the other perspective, the readers can be both host and the audience in some ways for being in the listing groups. The topic is housing and the discourse will take place around it.

From another lexical point of view, the word "look" appears ten times in almost all samples except in Sample 7 and Sample 8. It has become the feature of this listing genre that "looking" collocates with "for" and "to". While "looking for" is used to address potential readers as "Looking for someone to sublease my spot in Lexington Ridge next semester" (sample 6), "Looking to" is used to denote the activity of the author as in "Looking to sublease my 1 bedroom apartment" (sample 3). Instead of using the words "searching," "seeking," or other words containing the meaning of in need of something, the writers were determined to use the word "looking" as a default. As Swales (1990) has said that speech community is a group of speakers who share similar linguistic principles of behavior (p. 23), this choice shows that the writers are trying to get the message straight and adhering to speech community rule.

\section{B. Conciseness.}

There is a briefness tendency on how people are posting on the site. From the 10 samples being investigated, the highest word use is 169 words (in Sample 1), while the lowest word use is 65 words (in Sample 4). It is also interesting to see one of the samples is composed of only two sentences (Sample 6). The table below illustrates the finding further:

Table 1.

The number and the average of words, sentences, and fragmented sentences

\begin{tabular}{llllll}
\hline Sample & Words & Sentences & $\begin{array}{l}\text { Fragmented } \\
\text { Sentences }\end{array}$ & $\begin{array}{l}\text { Subject omitted from } \\
\text { fragments }\end{array}$ \\
\hline 1 & 169 & 7 & 2 & Apt. & \\
2 & 119 & 8 & 2 & I, apt. & \\
3 & 70 & 8 & 4 & I, apt. (2), you & \\
4 & 65 & 5 & 0 & You, price & \\
5 & 76 & 7 & 2 & I, lease, apt. & \\
6 & 67 & 2 & 3 & Lease, roommate & \\
7 & 81 & 7 & 0 & & \\
8 & 173 & 17 & 2 & I, you & \\
9 & 68 & 8 & 0 & & \\
10 & 77 & 8 & 2 & & \\
Total & 965 & 77 & 17 & & \\
Average & 96.5 & 7.7 & 1.7 & & \\
\hline
\end{tabular}

The average number of words and sentences is presented in Table 1. It can be seen that the average number of words in each posting is 96 and the average number of sentences is seven. In fact, one of the samples is composed 
of only two sentences (Sample 6). This pattern is quite similar to that found by a study of netvertising: that of average 40 statements, the statements comprise only one or two sentences (Fortanet, Palmer, and Posteguillo, 1999, pp. 103104). The number shows that the posts are relatively short.

Certainly, there are the reasons why the conciseness becomes characteristic of this kind of posting, and the reasons will be various. First, the site focuses on the housing and detailed information, so an introduction is not needed. Secondly, the design of the site has restricted rules for heading space. Finally, there is always an invitation for questions for those of people who are interested in the ads.

\section{Grammar analysis.}

There are two points that will be described in this part. They are sentence fragments and grammatical accuracy, which include run on sentences and punctuation. From the analysis, sentence fragments occur in almost all ten samples, with an average of 1.7 fragment sentences in each sample. As has been pointed out in Table 1, of the 77 sentences, 17 of them are fragmented, which is $22 \%$ of the overall samples. Detailed finding on conciseness can be seen in the figure below:

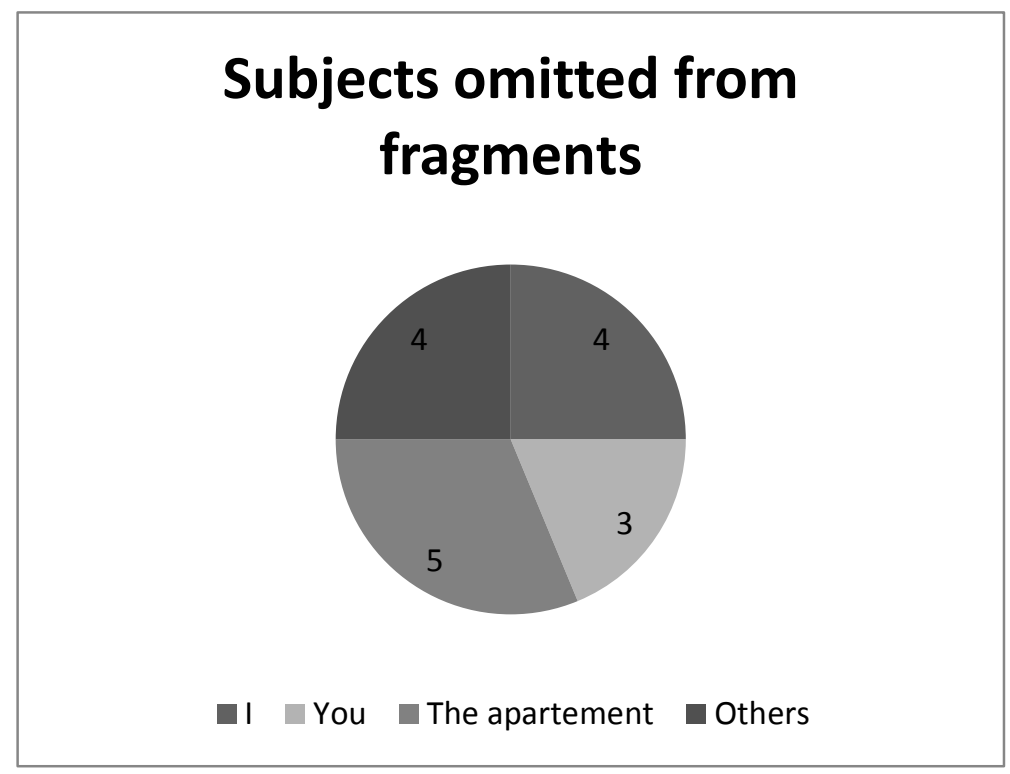

Figure 3. Subjects omitted from the fragments.

As can be seen from Figure 4, subject "I" is omitted four times in sample 2, 3, 6, and 10. For instance, "[I am] Looking for someone to sublease my spot in Lexington Ridge next semester" (sample 6). Subject "you" is omitted three times in sample 3, 5 and 10. For example, "[You] only have to pay electricity ( $\$ 20 / \mathrm{mo}) "$ (sample 3). Apartment as the subject is omitted 5 times in sample 1, 2, 3 (two times), and 6. Example: "[It is] 2 blocks from downtown, [it is] 10 minute walk from campus" (sample 3 ). The other subjects composing of price, lease ( 2 times), and roommate occur in sample 5,6 , and 8 . For example, "[The lease is] going from January 15th- February 15th, and so on" (sample 8).

From the data and the description above, it is revealed that subjects like "I", "you" and "the apartment" have been frequently omitted in the sentence fragments. First, 
there must be reasons why the authors tend to write sentences in fragments, then the analysis could be extended to the data collected.

Beside sentence fragments, posters also used run on sentences. Runon sentences occur in all samples. The given definition of run on sentence is "Run-ons, comma splices, and fused sentences are all names given to compound sentences that are not punctuated correctly" (Purdue, 2015). In this analysis, I choose one of the samples where the most case run on sentences happens. The following is the analysis on the misuse of coordinating conjunction in sample 1 (appendix).

\section{Sublease from 12/16-06/17}

\section{Michigan}

\$425 - Mount Pleasant,

....Very nice apartment with modern amenities and very clean with a nice walkout patio and sliding glass door. A number of things are included in the rent (available on their website or I will tell you if you call or text) and there are no extra fees. We are looking for people who need the apartment in late December or January and the lease that you would be taking over runs through the school year into May but you can continue that if you would like at the leasing office and they are very nice and flexible with everything. Contact Tyler at $810-922-0158$ if you are interested and we can talk more or you can just come out and see the place if you want. Thanks and I look forward to doing business with you.

Looking closely at one of the selected examples above, there are frequent incorrect uses of coordinating conjunction "and". Based on CelceMurcia and Larson-Freeman (1999), conjunction is the process of combining two equal constituents of the same category (p. 24). The sentences connected by coordinating conjunctions in this sample, however, are not grammatically equal. For example, in the compound sentences "with modern amenities and very clean" (in sample 1 above) are not grammatically equal. Conjunction "and" should connect the same part of speech, except the comma is maintained.

Considering how casual and localized this site can be, it is likely that the presence of spoken language played a role in this written discourse. Janoschka (2004) has stated that the characteristics of spoken language include the use of "simplified, abbreviated language, forms of personal user addressing such as questions, imperatives, personal pronouns and deictic terms to carry out their function" (p. 121). The conjunctions "and" and "but," common in spoken language, usually become the most frequent conjunctions in informal writing without worrying whether they are grammatical or not. In this local Facebook housing listing, this case occurs quite often.

\section{Conclusion and Future Study}

This study has generated some important findings because it reveals specific patterns of postings which include move analysis and language feature of local Facebook housing advertisement as explored in result and discussion section. There are two topics that have been analyzed in this paper. They are the generic structure (moves, briefness, and grammatical analysis) and the language features of the listing which include tense, pronoun, and 
lexical analysis. As Bhatia (1993) mentioned that the use linguistic resources are always flexible, yet the writers have to adhere to specifically standardized practices within the borderline of a specific genre so that the message can be conveyed to the reader (p. 51). Besides the fact that studies on casual short advertisements are still scarce, the findings are significantly valuable for the analyst and the audience to understand how such short posting play a discourse function in a Facebook discourse community.

Although the study is important as it has discovered the generic features that I have mentioned earlier, it cannot discover how effective this kind of advertisements is. This study cannot reveal whether the ads are successful in attaining prospective customers. Future comparative study on advertisements will potentially enlighten this case. Finally, although pedagogical applications are not explored in this paper, its findings could be productively applied in the classroom.

\section{References}

Anthony, L. (2014). AntConc (Version 3.4.3) [Computer Software]. Tokyo, Japan: Waseda University. Available from http://www.laurenceanthony.net/

Bhatia, Vijay K. (1993). Analyzing genre: language use in professional settings. London, UK: Longman group.

Bhatia, Vijay K. (2004). Worlds of written language: a genre-based view. London, UK: Continuum.

Celce-Murcia, M., \& Larsen-Freeman, D. (1999). The grammar book: An ESL/EF course (2nd ed.). Boston, MA: Heinle $\&$ Heinle.

Dean, A. (2014). Definition: Facebook. Retrieved from http://whatis.techtarget.com/defi nition/Facebook

Elizabeth (2015). What Is A Conjunction?.

http://www.english-grammarrevolution.com/what-is-aconjunction.html

Fortanet, I., Palmer, J. C., \& Posteguillo, S. (1999). The emergence of a new genre: Advertising on the internet (netvertising).Hermes, 23, 93113. Retrieved from http://search.proquest.com/docvi ew/85508427? accountid=10181

Janoschka, A. (2004). Web Advertising. New forms of communication on the Internet. Philadelphia, PA, USA: John Benjamins Publishing Company. Retrieved from

http://www.ebrary.comMartin, J. \& Rose, D. (2007). Working with discourse: Meaning beyond the clause. London: Equinox.

Nyyssonen, H. (2001). On the relationship of grammar and discourse: Secondary coding. Anglicana

Turkuensia, 23, 119-129. Retrieved from http://search.proquest.com/docvi ew/85541887? accountid=10181

Paltridge, B. (1996). Genre, text type, and the language learning classroom. ELT Journal, 50(3), 237-43. doi: 10.1093/elt/50.3.237

Purdue Online Writing Lab (2015). Run-ons - Comma Splices Fused Sentences. https://owl.english.purdue.edu/o wl/resource/598/02/

Swales, J. (1990). Genre analysis: English in academic and research settings. Cambridge, UK: Cambridge University Press. 
Swales, J. (2004). Research genres: Explorations and applications. Cambridge, UK: Cambridge University Press.
Yang, R. \& Allison, D. (2003). RAs in applied linguistics: Moving from results to conclusions. English for Specific Purposes, 22(4), 365-384. 